\title{
Effect of sedimentary facies and geological properties on thermal conductivity of Pleistocene volcanic sediments in Tokyo, central Japan
}

\author{
Takato Takemura $^{1,2} \cdot$ Minoru Sato $^{3} \cdot$ Takashi Chiba $^{3} \cdot$ Kyota Uemura $^{1,2} \cdot$ \\ Yoshiharu Ito $^{1,2} \cdot$ Ayako Funabiki $^{4}$
}

Received: 12 May 2015/Accepted: 2 February 2016/Published online: 25 February 2016

(c) Springer-Verlag Berlin Heidelberg 2016

\begin{abstract}
When ground source heat pump systems are installed underground, an estimate of the thermal conductivity is required to determine the desired total length of the heat exchanger (U-tube). Many large cities in Asia are built on Quaternary sediments, but the thermal conductivity of these sediments is not well understood. To measure the thermal conductivity of Pleistocene volcanic sediments in Tokyo, Japan, we discuss methods of measuring thermal conductivity and factors influencing the thermal conductivity of volcanic sediment, which has low quartz content. The results obtained from experiments using a drill core, borehole data and artificial sediment samples are as follows: (1) values of thermal conductivity predicted using water content, porosity or sand content can be underestimated in volcanic sediment or sediments with large amounts of magnetic minerals; (2) magnetic minerals have a higher thermal conductivity than quartz, so there is a relationship between magnetic susceptibility and thermal conductivity: (3) comparison of thermal conductivity measurements performed using box- and needle-type probes showed that the values measured using the former are comparatively larger. This decrease in thermal
\end{abstract}

Takato Takemura

takemura.takato@nihon-u.ac.jp

1 Geomechanics Lab, College of Humanities and Sciences, Nihon University, Setagaya, Tokyo, Japan

2 Core Research for Evolutionary Science and Technology, Japan Science and Technology Agency, Kawaguchi, Saitama, Japan

3 Graduate School of Life and Environmental Sciences, University of Tsukuba, Tsukuba, Ibaraki, Japan

4 Department of Mechanical Engineering, College of Engineering, Nihon University, Koriyama, Fukushima, Japan conductivity is explained by formation of air-filled cracks when the needle penetrates the sediment, as air has a lower thermal conductivity than sediment.

Keywords Thermal conductivity $\cdot$ Magnetic susceptibility · Volcanic sediment · GSHP

\section{Introduction}

The subsurface thermal environment is changed due to global warming (Taniguchi and Uemura 2005) as well as changes associated with urbanization such as underground construction of malls, transportation systems and sewerage networks (Menberg et al. 2013). Recently, to reduce carbon dioxide emissions, installations of ground source heat pumps (GSHP), a renewable/low-carbon technology, have been increasing globally (Lund et al. 2011; Banks 2012). GSHP systems comprise a ground heat exchanger, heat pump and distribution system. GSHP systems differ from air source heat pumps (air conditioners) in that the heat exchange is performed by subsurface sediments/rocks and underground water rather than outside air. There are two types of ground heat exchanger: open loop and closed loop (Ochsner 2007). Open-loop systems circulate water between two wells in an aquifer and require abundant groundwater. In closed-loop systems, a non-freezing fluid circulates through a U-tube, usually made of polyethylene, installed in a borehole. This type of system can be installed anywhere irrespective of the geological conditions. When a closed-loop GSHP system is installed underground in a borehole, the heat exchange performance is dependent on the thermal properties of the sediments/rocks. Therefore, estimation of the thermal properties of sediments/rocks at shallow depths $(<200-300 \mathrm{~m})$ in the installation area is 
important when designing a GSHP system. The thermal properties of sediments/rocks are thermal conductivity, specific heat capacity and coefficient of thermal diffusivity. Each property can be obtained if the other two are known, as two of the three properties are independent parameters. The thermal properties of sediments/rocks are basic physical properties and are important for engineering problems [e.g., heat exchange performance of GSHP (Liebel et al. 2012; Saito et al. 2014)], but also for scientific investigations of heat circulation and heat flux in the earth's crust (Sass et al. 1971; Pribnow and Sass 1995; Vosteen and Schellschmidt 2003; Goto and Matsubayashi 2009; Lin et al. 2011, 2014).

The thermal properties of sediments/rocks are related to their porosity, mineral composition, bulk density, water content and the geometric arrangement of their minerals. Many estimation models for soils, sediments and rocks have been proposed previously (de Vries 1963; Woodside and Messmer 1961; Drury and Jessop 1983; Kasubuchi 1984; Usowicz 1992; Saito et al. 2014). Estimation of thermal conductivity is important to determine heat transfer in sediments/rocks, and has been studied in many fields such as agriculture, marine geology, petroleum, and natural gas engineering. The depths addressed in previous studies have usually been a few meters $(<10 \mathrm{~m})$ for agriculture and a few kilometres $(<3 \mathrm{~km})$ for geology. However, as the intended depth of a GSHP is usually shallow $(<200-300 \mathrm{~m})$, there have been few reports of measured data with detailed lithologies for this depth compared with shallower or deeper strata.

The thermal properties of sediments/rocks depend on the geological background such as the mineral composition and sedimentary facies. To cite cases in Europe, a GSHP with dynamic thermal energy storage was installed in hard rock (mica gneiss, Silurian sediments and Ordovician sediments) in Norway (Liebel et al. 2012), a borehole thermal energy store was installed in fractured Triassic sedimentary rock with fractures in Germany (Mielke et al. 2014) and a GSHP system was installed in a chalk layer in London, UK (Busby et al. 2009; Arthur et al. 2010). The main lithology in which GSHP systems are installed is fractured sedimentary rocks in Europe, which are countries in the process of introducing GSHP systems. However, many large cities in Asia, such as Tokyo, Osaka and Bangkok, are built on Quaternary sediments. The Quaternary sediments of Tokyo, Japan, are composed of unlithified clay, silt and sand with a mineral composition of mafic minerals and/or tuffaceous sand, because the hinterland is formed mainly of pyroclastic material and volcanic ash sediments.

Appropriate estimation of the thermal properties of sediments/rocks is important during the design of a GSHP system as the total length of the U-tube used depends on thermal properties of the surrounding domain. In this study, the following properties were measured using bored core samples and/or a measuring borehole drilled in Tokyo, central Japan: (1) geological properties (dry density, water content, soil particle density, porosity, grain size distribution, loss on ignition, magnetic susceptibility, mineral content and needle penetration resistance) and electric resistivity; (2) thermal properties (thermal conductivity and heat capacity); and (3) the effective thermal conductivity, which is calculated using the thermal response test (TRT). Furthermore, laboratory experiments using artificial specimens were conducted to clarify the effect of mineral content, with an emphasis on the effect of magnetic mineral content on thermal conductivity. Lastly, the study concludes by discussion on the appropriate estimation model for thermal conductivity of volcanic sediments adopting the measured data.

\section{Materials and methods}

\section{Description of site and boreholes}

The research area is Setagaya district, Tokyo, central Japan (Fig. 1); altitude $41.202 \mathrm{~m}$, latitude $35^{\circ} 39^{\prime} 49.62^{\prime \prime} \mathrm{N}$, longitude $139^{\circ} 38^{\prime} 04.91^{\prime \prime} \mathrm{E}$ and located on the Musashino surfaces of the Musashino upland (Oka et al. 1984). In the research area, two boreholes (holes 1 and 2) were drilled down to a depth of $50 \mathrm{~m}$ below ground level. At this stage, an undisturbed core sample was obtained from hole 1 to determine the stratigraphy, facies as well as geological and thermal properties. The diameter of the core taken from hole 1 was $66 \mathrm{~mm}$ while no core sample was obtained from hole 2 and instead, a U-tube heat exchanger with a thermocouple was installed to conduct TRT (Fig. 2). Hole 2 was drilled with a $115-\mathrm{mm}$ diameter and the U-tube was installed at the center of the borehole with coarse-grained silica. The internal and external diameters of the U-tube made from high-density polyethylene were 27 and $33 \mathrm{~mm}$, respectively.

\section{Measurement of geological and thermal properties}

In this study, the geological properties were basic physical properties (dry density, water content, soil particle density, grain size distribution and loss on ignition), mineral content, magnetic susceptibility and needle penetration resistance. The thermal properties were categorized as thermal conductivity and heat capacity. Using undisturbed cores $(1 \mathrm{~m} \times 50$ cores) from hole 1 , the cores were first split in half along their longitudinal axes and the geological properties were measured using one half of the cores. The other half was then employed to observe stratigraphy and facies. During the procedure, some cores taken from unit 1 
Fig. 1 a Location map of the research area in Tokyo, central Japan. b Geological map of the research area

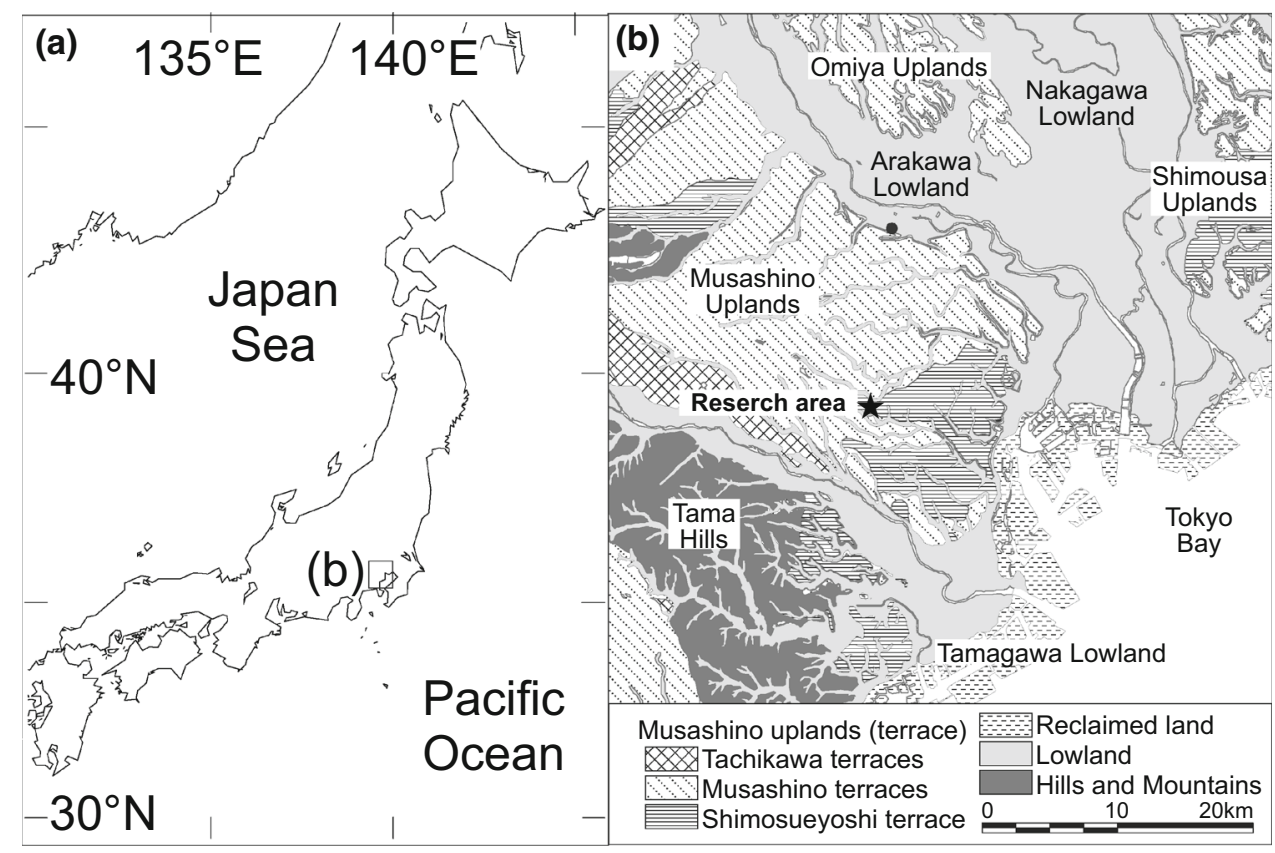

were hard to split, the outer surfaces of which were scraped off for the measurements of geological properties via observation of stratigraphy and facies. Figure 3 shows the procedure for the measurement of geological and thermal properties. Since obtaining specimen from the gravel unit 2 (Fig. 2) was rather difficult, the geological properties (except for grain size distribution) could not be determined. Hence, electrical well logging was performed at hole 1 after obtaining the core samples. Details regarding measurement methods used for each property are described below:

- Dry density Specimens were obtained from the split core using $7-\mathrm{cm}^{3}$ plastic cubes at intervals of $0.25 \mathrm{~m}$. Three specimens were sampled at each sampling point to reduce the measurement error due to total volume, and the total measurement volume $V$ was $21 \times 10^{3}$ $\mathrm{mm}^{3}$. After sampling, the specimen was heated to $110 \pm 5{ }^{\circ} \mathrm{C}$ for at least $24 \mathrm{~h}$, and the mass of soil solids $m_{\mathrm{s}}$ was measured. Afterwards, dry density $p_{\mathrm{d}}$ was measured as $\left(m_{s} / V\right) \times 100(\%)$.

- Water content Specimens were sampled from the split core at intervals of $0.25 \mathrm{~m}$ for $0-20 \mathrm{~m}$, and at intervals of $0.50 \mathrm{~m}$ for $21-50 \mathrm{~m}$. Once sampling was completed, wet soil mass $m$ was measured, which was about $100 \mathrm{~g}$ for every specimen. Subsequently, the corresponding soil solid masses $m_{\mathrm{s}}$ for the specimens were measured following the drying procedure described earlier. Eventually, water content $w$ defined as the ratio of contained water mass to that of dry soil was calculated by $\left[\left(m-m_{\mathrm{s}}\right) / m_{\mathrm{s}}\right] \times 100(\%)$ in which $\left(m-m_{\mathrm{s}}\right)$ represents pore water mass.
- Soil particle density Measurement of soil particle density $p_{\mathrm{s}}$ was conducted after measurement of wet and dry densities at intervals of $0.25 \mathrm{~m}$. The measurements were carried out using a helium pycnometer (AccuPyc 1330, Micromeritics Instrument Corporation).

- Porosity As it was difficult to determine porosity directly, the formula $\left[1-\left(\rho_{\mathrm{d}} / \rho_{\mathrm{s}} w\right)\right] \times 100(\%$; JGS 2009) was employed to obtain the porosity values.

- Grain size distribution The grain size distributions were measured using a laser beam particle size analyser (model SALD-3000S, Shimadzu Co. Ltd., measurement range $8-3000-\mu \mathrm{m}$ diameter) for grains smaller than $2000 \mu \mathrm{m}$. Grains larger than $2000 \mu \mathrm{m}$ were measured by sieving at intervals of $0.5 \mathrm{~m}$ for $0-20 \mathrm{~m}$ and at intervals of $1 \mathrm{~m}$ for 21-50 m (JGS 2009).

- Loss on ignition Loss on ignition (LOI) is one of the common methods to estimate organic matter in soil. Since the same specimens for earlier dry density measurements were used, each sampling point included three specimens. The mass of specimens was about $5 \mathrm{~g}$ taken from the dried specimens. After measuring the mass of the dried specimens, $m_{\mathrm{a}}$, they were placed in a crucible and heated to $750 \pm 50{ }^{\circ} \mathrm{C}$ for $1 \mathrm{~h}$ using a muffle furnace. Subsequently, the specimens were taken out of the furnace and left to cool to room temperature. Finally, the mass of the heated specimen, $m_{\mathrm{b}}$, was measured and LOI was calculated as $\left[\left(m_{\mathrm{a}}-\right.\right.$ $\left.\left.m_{\mathrm{b}}\right) / m_{\mathrm{a}}\right] \times 100(\% ;$ JGS 2009).

- Magnetic susceptibility Magnetic susceptibility measurements were conducted at intervals of $0.25 \mathrm{~m}$ using 


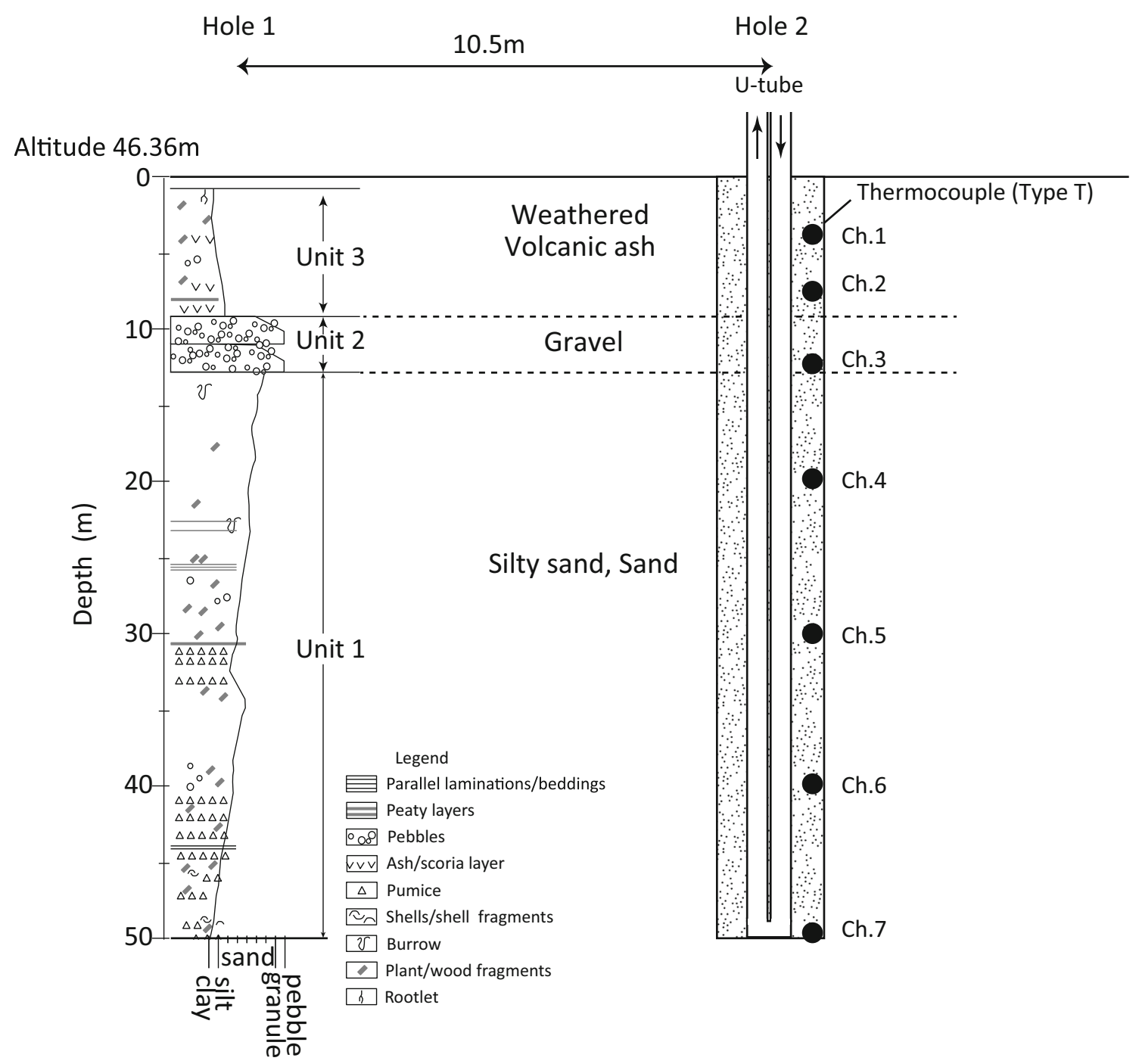

Fig. 2 Schematic diagram of the two investigated boreholes. Core samples were collected from hole 1 and a U-tube heat exchanger was installed in hole 2

a portable magnetic susceptibility meter (Geofizika Brno, Kappameter Model KT-5). The unit of susceptibility was dimensionless SI units. The split core surface was trimmed to a flat surface to provide the required measurement area (60-mm diameter). The split core used for the magnetic susceptibility measurements was the other half of the split core used for the measurements listed above.

- Mineral content The mineral content of specimens was measured after the water content had been determined at 15 depths $(1.3,1.8,2.8,4.2,7.2,8.7,12.5,15.5,18.0$, 25.0, 28.5, 31.0, 36.7, 42.0 and $48.9 \mathrm{~m}$ ). First, organic matter was decomposed by hydrogen peroxide after clay had been removed using ultrasonic cleaning. Second, the specimens were dried in a ventilation dryer at $60{ }^{\circ} \mathrm{C}$ followed by sieving to $63 \mu \mathrm{m}$. Finally, randomly selected particles were observed under a microscope, and the mineral species were identified. These included light minerals (quartz and feldspar), heavy minerals [hornblende, pyroxene, olivine and magnetic mineral (magnetite and hematite)], volcanic glass and rock fragments.

- Thermal properties The thermal conductivity $\lambda$ of sediments was measured by two different kinds of probes, box (BP)- and needle (NP)-type probes, using the undisturbed core from hole 1 at 59 depths for boxtype probe and 28 depths for needle-type probe. The measurement procedures for both probes obey the transient hot-wire method posited upon the line source model, which is expressed by the following equation (Ingersoll et al. 1948): 
Fig. 3 Schematic image for the measurement procedure of undisturbed core taken from hole 1 (split core case)

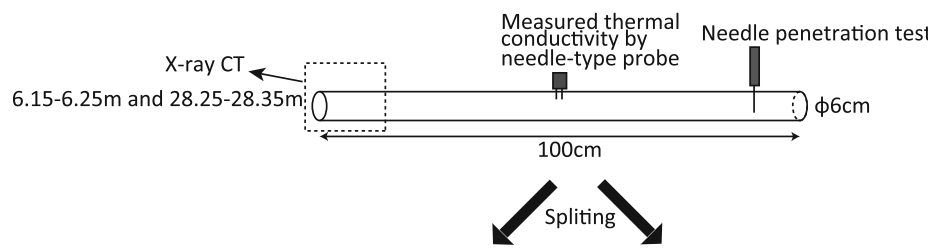

(1) Observation

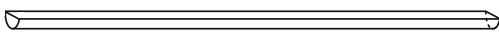

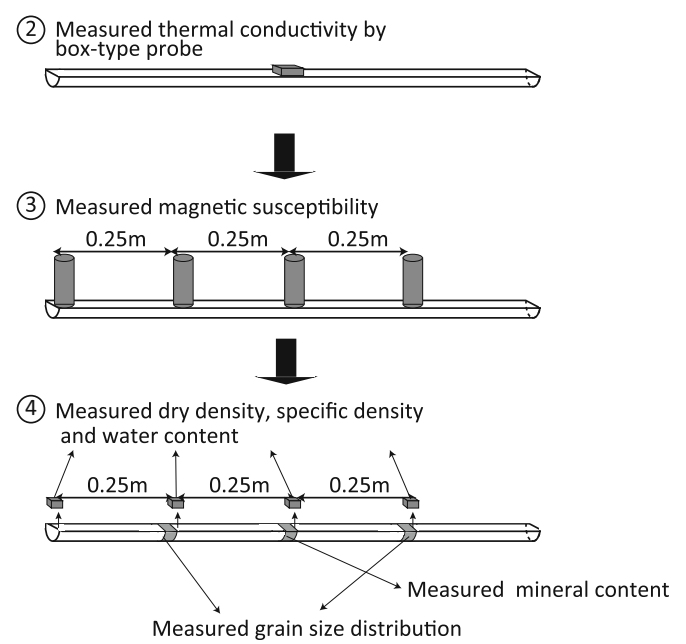

$\lambda=Q \cdot \frac{\ln \left(t_{2} / t_{1}\right)}{4 \pi\left(T_{1}-T_{2}\right)}$

where $Q$ is heat flux $\left(\mathrm{Wm}^{-2}\right), t$ is time (s) and $T$ is temperature $\left({ }^{\circ} \mathrm{C}\right)$.

For the thermal conductivity measured by box-type probe $\lambda_{\mathrm{BP}}$, the measurement device used was a quick thermal conductivity meter (QTM-500, Kyoto Electronic Manufacturing Co., Ltd.) and the probe was calibrated using a quartz standard. The probe contact area was set at $40 \times 100 \mathrm{~mm}$, which is the required area to obtain reliable thermal conductivity measurements using the box-type probe (Galson et al. 1987; Tadai et al. 2009).

For the thermal conductivity measured by needle-type probe $\lambda_{\mathrm{NP}}$, the measurement device used was a portable KD2 Pro thermal probe (Decagon Devices, Inc.). The probe used for this study has twin needles and can be used to measure thermal conductivity and heat capacity. In addition, the specimens at 6.15 and $28.25 \mathrm{~m}$ were observed by microfocus X-ray computed tomography (XS450-ACTIS, TESCO Co., Ltd.) to confirm being inside the specimen when inserting the needle probe.

- Needle penetration resistance The needle penetration test is a non-destructive index test to estimate physicomechanical properties such as the uniaxial compression strength of soil and/or soft rock. The device used for needle penetration testing was an ISRM-suggested device (Ulusay et al. 2014). The needle penetration index (NPI) was measured at intervals of about $3 \mathrm{~m}$ in the split core before specimens were sampled for the measurements listed above.

- Electric resistivity To confirm the aquifer layer and underground water level, the electrical well logging test was performed. The microresistivity log method was adopted (Ellis and Singer 2007).

\section{Thermal conductivity measured by thermal response testing}

Thermal response tests (TRTs) were performed to obtain the effective thermal conductivity $\lambda_{\text {eff }}$, which is the thermal conductivity measured in situ, in hole 2. A U-tube heat exchanger was placed in hole 2 , and thermocouples ( $\mathrm{T}$ type; accuracy $\left.\pm 0.5^{\circ} \mathrm{C}\right)$ were buried at 7 depths $(3,7,12$, $20,30,40$ and $50 \mathrm{~m}$ ), which were placed laterally on the Utube in hole 2 (Fig. 2). In the TRT, a constant thermal load [electric power for heating: $1.755 \pm 0.265(\mathrm{~kW})$, flow rate: $\left.12.19 \pm 0.18\left(\mathrm{~L} \mathrm{~min}^{-1}\right)\right]$ was applied to the fluid circulated in the U-tube for 3 days, and the fluid temperature was measured. The obtained data were plotted on the average fluid temperature between inlet and outlet of the Utube as a function of the natural logarithm of time (days). Then, the slope $n$ was defined by the linear part of the plotted diagram and was calculated by $n=\ln \left(t_{1} / t_{2}\right) /$ $\left(T_{1}-T_{2}\right)$, where $T_{1}-T_{2}$ is the temperature difference between $t_{1}$ and $t_{2}$. Using $n$, the effective thermal conductivity $\lambda_{\text {eff }}$ was evaluated by the line source model (Wagner 
and Clauser 2005; Lee et al. 2012), and Eq. (1) can be rewritten as:

$\lambda_{\text {eff }}=\frac{Q}{4 \pi} n$.

In this study, we assumed that the temperature of a thermocouple placed laterally on the U-tube was roughly in accordance with that of the circulating fluid. Hence, the diagram was plotted for seven depths, and $\lambda_{\text {eff }}$ values were calculated using Eq. (2).

\section{Thermal conductivity measured using artificial samples}

To clarify the effect of magnetic mineral content on thermal conductivity, water-saturated artificial sediment samples containing magnetite and Toyoura sand were prepared and used for measurements of thermal conductivity. The magnetite used is a reagent product $\left(\mathrm{Fe}_{3} \mathrm{O}_{4}\right.$, Wako Pure Chemical Industries, Ltd.) with a grain size of 250-750 $\mu \mathrm{m}$. Toyoura sand, a standard sand in Japan, was also used. This sand is composed of $72 \%$ quartz, $25 \%$ feldspar and $3 \%$ magnetic minerals (magnetite and/or hematite). The grain size of Toyoura sand is $250-750 \mu \mathrm{m}$. The thermal conductivity values for the typical minerals in sediments are summarized in Table 1 . The volume of each artificial specimen was the same to ensure constant porosity of all specimens. A total of 25 artificial specimens were prepared with magnetite fractions between 0 and $4 \mathrm{wt} \%$. The total magnetite fraction was between 3 and $7 \mathrm{wt} \%$ because of the $3 \mathrm{wt} \%$ magnetite fraction in the Toyoura sand. The thermal conductivity for artificial specimen $\lambda_{\text {Art }}$ was measured using the box-type probe and the magnetic susceptibility was measured. Here, the thermal conductivity of the total magnetite fraction equal $0 \mathrm{wt} \%$ is $\lambda_{\text {Int }}$. After measuring $\lambda_{\text {Art }}$ and $\lambda_{\text {Int }}$, the magnetic susceptibility was measured. Measurements of the $\lambda_{\text {Art }}, \lambda_{\text {Int }}$ and magnetic susceptibility were taken thrice to obtain mean values.

\section{Results}

\section{Geological setting}

Undisturbed core samples obtained from hole 1 were split immediately and the facies were described in detail (Fig. 3). The stratigraphic formations are classified into three units (units 1-3) from the oldest to the youngest as follows (see Fig. 2).

Unit $1(50.0-12.7 \mathrm{~m})$ : This unit is marine sediments of early to middle Pleistocene age, named the Kazusa Group. The thickness of the Kazusa Group is up to $3000 \mathrm{~m}$ in the area around Tokyo, and the sediments are the infill of the Plio-Pleistocene forearc basin (Ito 1998). The upper layer of this unit consists of bluish-grey silty sand with coarser grains underlying fine silt. The lower part is comprised of mollusc shell fragments and organic material which, contrary to the upper layer, increases in fineness with depth by gradual change from black silt to greyish-brown coarse sand.

Unit $2(12.7-9.0 \mathrm{~m})$ : This unit is Late Pleistocene terrace gravel, called the Musashino gravel layer. The
Table 1 Thermal conductivities of the typical minerals in sediments at room temperature

\begin{tabular}{lll}
\hline Minerals & Thermal conductivity & References \\
& $\mathrm{Wm}^{-1} \mathrm{~K}^{-1}$ & \\
\hline $\begin{array}{l}\text { Light minerals } \\
\text { Quartz }\end{array}$ & 7.7 & Horai (1971) \\
Feldspar & $1.2-3.6$ & Horai (1971) \\
Dolomite & 5.5 & Horai (1971) \\
Muscobite & $2.2-2.5$ & Horai (1971) \\
Biotite & $1.7-2.3$ & Horai (1971) \\
Heavy minerals & & \\
Hornblende & $2.5-3.1$ & Horai (1971) \\
Pyroxenes & $3.8-5.6$ & Horai (1971) \\
Olivine & $3.2-5.2$ & Horai (1971) \\
Pyrite & 19.2 & Horai (1971) \\
Magnetite & $5.1-20$ & Horai (1971), Akiyama et al. (1991), \\
& $11.3-17$ & Mølgaard and Smeltzer (1971) \\
Hematite & Horai (1971), Akiyama et al. (1991) \\
Water & 0.6 & Schön (1996) \\
Air & 0.024 & Schön (1996) \\
\hline
\end{tabular}

${ }^{a}$ Magnetic mineral 
sediments consist of medium to coarse sand and gravels with clast diameters of $20-50 \mathrm{~mm}$.

Unit $3(9.0-0.0 \mathrm{~m})$ : This unit consists of weathered volcanic ash deposited in the Late Pleistocene, called the Musashino Loam. The Musashino Loam consists of clay minerals formed as a result of weathering, and mafic minerals. At a depth of 9.0-8.7 m, a bluish-grey silty clay layer with plant fragments is observed. This clay layer is usually impermeable, and the underground water above this layer is unconfined groundwater. Since the groundwater level was $4.75 \mathrm{~m}$ from the surface, any depth larger than that was considered water-saturated in the electric resistivity study while shallower depths were deemed unsaturated.

These stratigraphic formations, Pleistocene marine sediment-terrace-gravel-weathered volcanic ash, are typical of the shallow geology in the upland around Tokyo (Suzuki et al. 2011).

\section{Depth profiles of the geological and thermal properties}

Figure 4 shows a profile of mineral content with depth in units 1 and 3. In unit 1 , the sediments mainly consist of feldspar and rock fragments, with many of the rock fragments being pyroclastic material such as pumice. In the upper part of unit 3 , heavy minerals (pyroxene, hornblende and olivine) account for a substantial fraction, and light minerals (quartz and feldspar) are more abundant than heavy minerals in the lower part of the layer. Note the quartz content in both units is low.

Figure 5 shows depth profiles of water content, porosity, grain size distribution, loss on ignition, magnetic susceptibility, thermal conductivity, heat capacity, needle penetration index and electric resistivity measured by the two probes and the NPI. Table 2 summarizes thermal conductivity values for all specimens. The porosity was calculated using the soil particle density and dry density. No specimens for measuring these properties (except for grain size distribution and electric resistivity) could be obtained for unit 2 as it was comprised of gravel sediments. The electric resistivity results show that the groundwater level is at about $4.75 \mathrm{~m}$ below ground level, and there is relatively abundant groundwater in unit 2 . The main lithology in unit 1 is sand and silty sand. Relatively lower water content was observed at depths between 20.0 and $25.0 \mathrm{~m}$, and the porosity was almost constant with depth. In addition, the NPI is highly variable. At depths of 13.5-22.0 m, higher values of magnetic susceptibility and thermal conductivity were observed compared with those of the deeper part. Some levels show a high magnetic susceptibility value despite the measurements of mineral content showing a

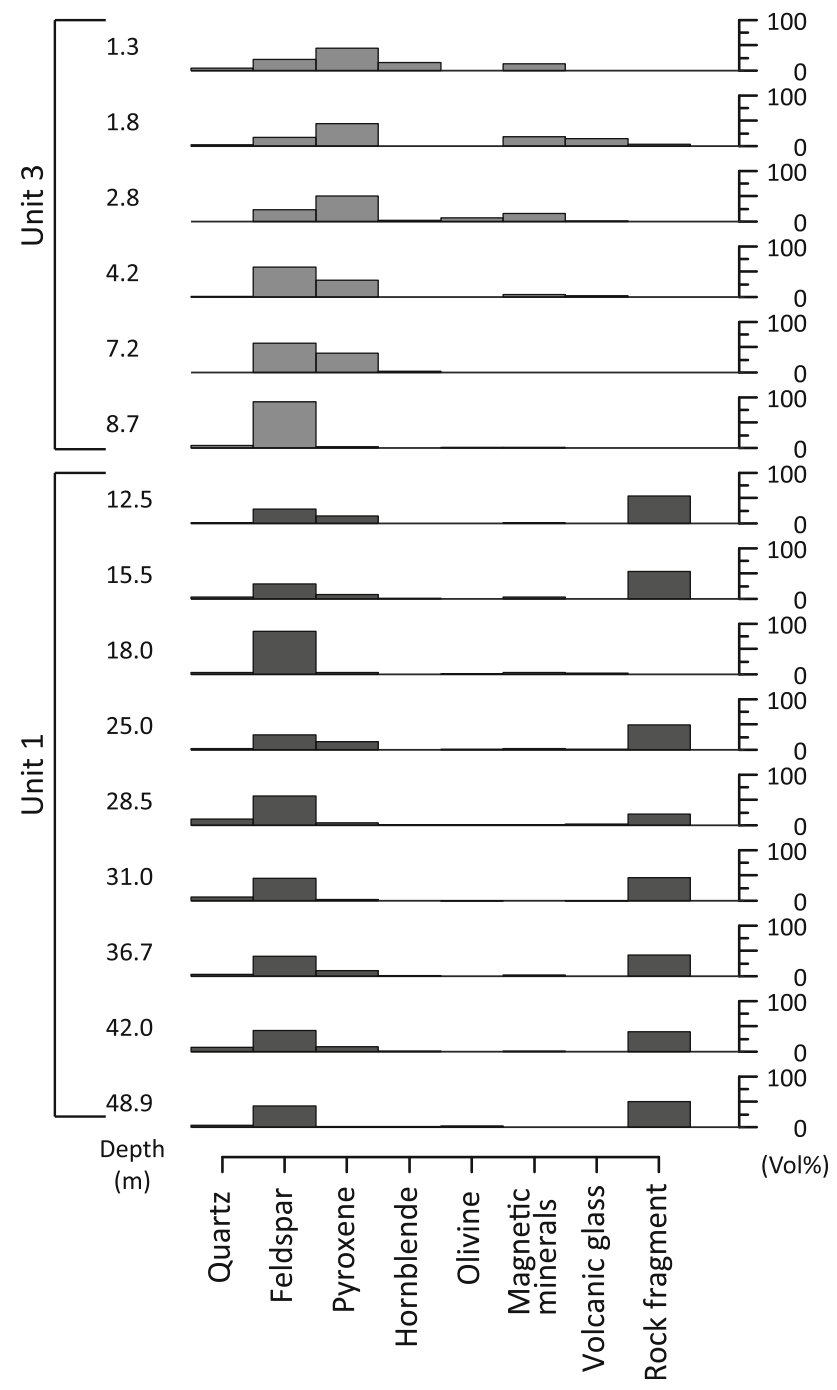

Fig. 4 Profile of the mineral content measured in undisturbed core samples obtained from hole 1

low level of magnetic minerals (only a few percent). This is because magnetic minerals are included in rock fragments, which are present at a level of about $50 \%$ in unit 1 , even if magnetic minerals were not measured directly. The relationship between magnetic susceptibility and thermal conductivity will be described in detail below. In unit 3, the main lithology was silt and silty clay, and the water content, porosity and magnetic susceptibility gradually increased towards the surface in unit 3 . The reason for this is that unit 3 consists of weathered volcanic ash with a high organic matter content $(\sim 10-22 \%)$; therefore, the NPI was unmeasurable $(\mathrm{NPI}=0)$. For both units, the heat capacity was almost constant with a mean value of 3.05 $\mathrm{MJm}^{-3} \mathrm{~K}^{-1}$.

Figure 6 shows the depth profile of $\lambda_{\text {eff }}$. The overall mean value of $\lambda_{\text {eff }}$ is $1.65 \mathrm{Wm}^{-1} \mathrm{~K}^{-1}$, and the mean values 


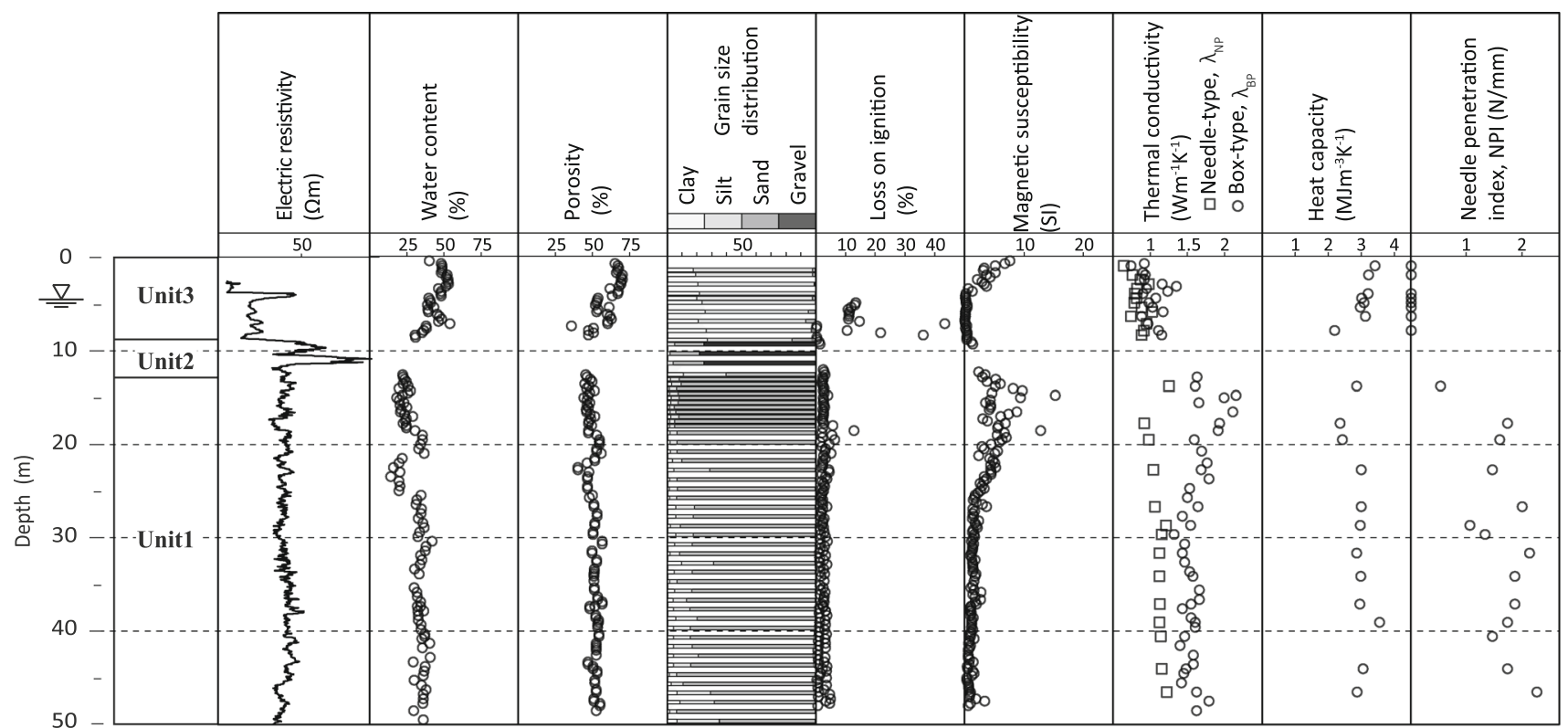

Fig. 5 Depth profile of water content, porosity, grain-size distribution, loss on ignition, magnetic susceptibility, thermal conductivity, heat capacity, needle penetration index and measured electric resistivity using undisturbed core samples obtained from hole 1 . In this study, dry density and soil particle density were measured and

of $\lambda_{\text {eff }}$ for each unit are 1.64, 2.05 and $1.48 \mathrm{Wm}^{-1} \mathrm{~K}^{-1}$ for units 1,2 and 3 , respectively. The relatively high $\lambda_{\text {eff }}$ value of unit 2 , which is a gravel layer acting as an aquifer compared with those of the other layers, can be attributed to the abundant groundwater flow in that layer. This may be explained by the additional impact of convective heat transport to the already existing conductive heat exchange affecting $\lambda_{\text {eff. }}$.

\section{Relationship between thermal conductivity and magnetic susceptibility}

The relationship between magnetic mineral fraction and magnetic susceptibility is shown in Fig. 7a, demonstrating that magnetic susceptibility is adequately correlated with magnetite fraction in the sediment samples. Figure $7 \mathrm{~b}$ shows the effect of magnetic susceptibility on $\lambda_{\text {Art }}$ normalized by the thermal conductivity of intact Toyoura sand $\lambda_{\text {Int }}$. The error bar of magnetic susceptibility shows the minimum and maximum values, and the measurement error of thermal conductivity for all specimens is within \pm 0.02 $\mathrm{Wm}^{-1} \mathrm{~K}^{-1}$. The thermal conductivity increases with increasing magnetic susceptibility; thus, thermal conductivity depends on the magnetic mineral fraction of the sediment. used to calculate porosity (not illustrated). As can be seen, electric resistivity results indicated that the groundwater level was $4.75 \mathrm{~m}$ below the surface. Hence, any depths less than $4.75 \mathrm{~m}$ were considered unsaturated

\section{Discussion}

\section{Measurement of thermal conductivity for Pleistocene sediments}

Comparison of methodologies for laboratory measurement of thermal conductivity, i.e., the difference between the thermal conductivity measured by box-type probe $\lambda_{\mathrm{BP}}$ and the thermal conductivity measured by needle-type probe $\lambda_{\mathrm{NP}}$, was conducted in some previous studies (Horai 1981). In this study, however, the ratio of $\lambda_{\mathrm{BP}}$ and $\lambda_{\mathrm{NP}}, \lambda_{\mathrm{BP}} / \lambda_{\mathrm{NP}}$, is used for comparing the needle- and box-type probes. Horai (1981) reported thermal conductivity values measured by both probe types in marine sediment cores, and the $\lambda_{\mathrm{BP}} / \lambda_{\mathrm{NP}}$ was about 1.23 , which was thought to be the result of pore water evaporation. This finding indicates that the needletype probe is less affected by evaporation than the box-type probe, because evaporation occurs on the specimen surface. However, $\lambda_{\mathrm{BP}} / \lambda_{\mathrm{NP}}$ should be less than 1 as the thermal conductivity of air is much smaller than that of water. Tadai et al. (2009) measured $\lambda_{\mathrm{BP}} / \lambda_{\mathrm{NP}}$ using sedimentary rock and reported a value of $\lambda_{\mathrm{BP}} / \lambda_{\mathrm{NP}}=1.55$. The difference may have been caused by underestimation of $\lambda_{\mathrm{NP}}$ because the space between the specimen and needle was filled with air. 
Table 2 List of thermal conductivity measured using the box-type probe $\lambda_{\mathrm{BP}}$, and that measured using the needle-type probe $\lambda_{\mathrm{NP}}$

\begin{tabular}{|c|c|c|c|c|c|c|c|c|c|}
\hline & Depth (m) & $\lambda_{\mathrm{BP}}$ & $\lambda_{\mathrm{NP}}$ & $\lambda_{\mathrm{BP}} / \lambda_{\mathrm{NP}}$ & & Depth (m) & $\lambda_{\mathrm{BP}}$ & $\lambda_{\mathrm{NP}}$ & $\lambda_{\mathrm{BP}} / \lambda_{\mathrm{NP}}$ \\
\hline \multirow[t]{10}{*}{ Unit 3 (unsaturated) } & 1.25 & 0.92 & - & - & Unit 1 & 24.50 & 1.79 & - & - \\
\hline & 1.50 & 0.74 & 0.64 & 1.16 & & 25.50 & 1.53 & - & - \\
\hline & 2.25 & 0.90 & - & - & & 26.50 & 1.50 & - & - \\
\hline & 2.50 & 0.93 & 0.76 & 1.22 & & 27.50 & 1.64 & 1.06 & 1.55 \\
\hline & 3.00 & 0.92 & 0.87 & 1.06 & & 28.50 & 1.43 & - & - \\
\hline & 3.50 & 1.16 & 0.98 & 1.18 & & 29.50 & 1.54 & 1.21 & 1.27 \\
\hline & 3.75 & 1.35 & - & - & & 30.50 & 1.32 & 1.15 & 1.15 \\
\hline & 4.00 & 0.95 & 0.82 & 1.16 & & 1.15 & 1.46 & - & - \\
\hline & 4.25 & 1.23 & - & - & & 32.50 & 1.43 & 1.12 & 1.28 \\
\hline & 4.50 & 0.90 & 0.79 & 1.14 & & 33.50 & 1.46 & - & - \\
\hline \multirow[t]{8}{*}{ Unit 3 (saturated) } & 5.00 & 1.07 & 0.81 & 1.32 & & 34.50 & 1.53 & - & - \\
\hline & 5.50 & 0.98 & 0.78 & 1.26 & & 35.00 & 1.57 & 1.12 & 1.40 \\
\hline & 6.00 & 1.03 & 0.88 & 1.17 & & 36.50 & 1.66 & - & - \\
\hline & 6.50 & 1.17 & 1.02 & 1.15 & & 37.50 & 1.66 & - & - \\
\hline & 7.00 & 0.88 & 0.74 & 1.19 & & 38.00 & 1.55 & 1.13 & 1.37 \\
\hline & 7.75 & 0.97 & 0.95 & 1.02 & & 38.50 & 1.43 & - & - \\
\hline & 8.50 & 1.11 & 0.91 & 1.22 & & 39.50 & 1.55 & - & - \\
\hline & 9.00 & 1.15 & 0.88 & 1.31 & & 40.00 & 1.60 & 1.12 & 1.43 \\
\hline \multirow[t]{12}{*}{ Unit 1} & 13.50 & 1.63 & - & - & & 40.50 & 1.60 & - & - \\
\hline & 14.50 & 1.60 & 1.25 & 1.28 & & 41.50 & 1.46 & 1.14 & 1.28 \\
\hline & 15.50 & 2.15 & - & - & & 42.50 & 1.40 & - & - \\
\hline & 15.75 & 1.99 & - & - & & 43.50 & 1.58 & - & - \\
\hline & 16.25 & 1.65 & - & - & & 44.50 & 1.58 & - & - \\
\hline & 17.25 & 2.11 & - & - & & 45.00 & 1.48 & 1.15 & 1.29 \\
\hline & 18.50 & 1.93 & 0.92 & 2.10 & & 45.50 & 1.45 & - & - \\
\hline & 19.25 & 1.91 & - & - & & 46.50 & 1.42 & - & - \\
\hline & 20.25 & 1.59 & 0.98 & 1.62 & & 47.50 & 1.62 & 1.22 & 1.33 \\
\hline & 21.50 & 1.69 & - & - & & 48.50 & 1.79 & - & - \\
\hline & 22.75 & 1.76 & - & - & & 49.50 & 1.62 & - & - \\
\hline & 23.50 & 1.68 & 1.04 & 1.62 & & & & & \\
\hline
\end{tabular}

$\lambda_{\mathrm{BP}} / \lambda_{\mathrm{NP}}$ is the ratio of $\lambda_{\mathrm{BP}}$ and $\lambda_{\mathrm{NP}}$
In this study, $\lambda_{\mathrm{BP}}$ was observed to be larger than $\lambda_{\mathrm{NP}}$ in all samples, for which the mean values of $\lambda_{\mathrm{BP}} / \lambda_{\mathrm{NP}}$ were 1.48 in unit 1 and 1.18 in unit 3 (Fig. 8). The reason for this difference could be attributed to the gapping induced by asperities between the specimen and needle probe which becomes pronounced in harder specimens in contrast to soft sediments embodying the needle-type probe. In other words, the box-type probe test was less sensitive than the needle-type probe to the hardness of the specimen under study, as the variation of the values for ratio $\lambda_{\mathrm{BP}} / \lambda_{\mathrm{NP}}$ was significantly lower for the former. Figure 9 shows the relationship between $\lambda_{\mathrm{BP}} / \lambda_{\mathrm{NP}}$ and NPI in which the ratio $\lambda_{\mathrm{BP}} / \lambda_{\mathrm{NP}}$ increased with NPI. This trend indicates that $\lambda_{\mathrm{BP}} / \lambda_{\mathrm{NP}}$ depends on NPI which is a measure of the degree of consolidation or cementation of sediment. Cracks were observed to form around the needle insertion points in a unit 1 specimen, which was comprised of consolidated or cemented sediment in the microfocus $\mathrm{X}$-ray computed tomography image (Fig. 10a). The needle was in close contact with sediments in the unit 3 specimen, which was weathered volcanic ash, in microfocus X-ray computed tomography images (Fig. 10b). Thus, $\lambda_{\mathrm{NP}}$ is underestimated for consolidated or cemented sediments such as Pleistocene or older sandy sediments, because of the air-filled cracks generated when the needle penetrates the sediment. In addition, the mean value of $\lambda_{\mathrm{BP}}$ and $\lambda_{\mathrm{NP}}$ in unit 1 were 1.62 and $1.12 \mathrm{Wm}^{-1} \mathrm{~K}^{-1}$, respectively. Hence, in comparison with $\lambda_{\mathrm{NP}}, \lambda_{\mathrm{BP}}$ was closer in magnitude to $\lambda_{\text {eff }}$ in unit $1\left(=1.64 \mathrm{Wm}^{-1} \mathrm{~K}^{-1}\right)$. Therefore, $\lambda_{\mathrm{BP}}$ values measured using core specimens were similar to those of $\lambda_{\text {eff }}$ for consolidated/cemented sediments. 
Effective thermal conductivity

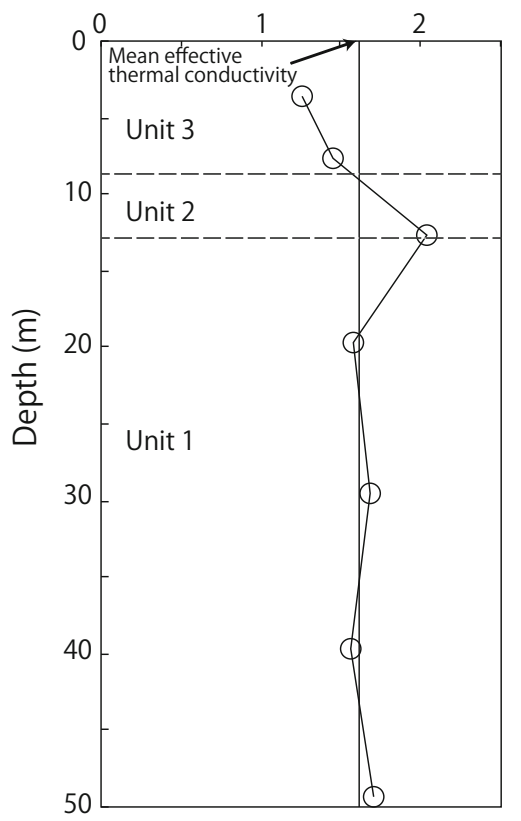

Fig. 6 The measured $\lambda_{\text {eff }}$ profile at hole 2 obtained using a TRT

\section{Factors influencing thermal conductivity in volcanic sediments}

The factors influencing thermal conductivity are the subject of ongoing discussion with the aim of estimation of thermal conductivity using measurable physical properties. For soils with varying moisture content, de Vries (1963) proposed a model using the volumetric fractions of each component (i.e., quartz, organic matter, water and air) and the geometric shape factor for a given solid phase. For

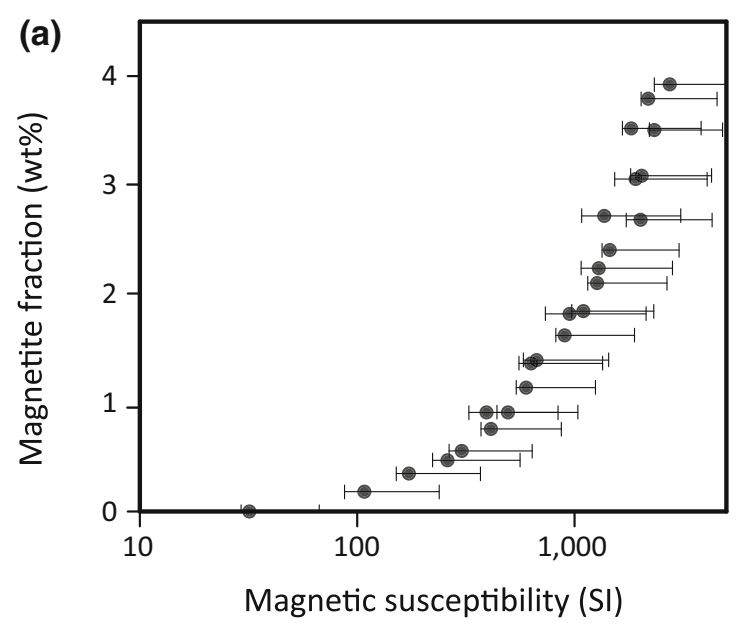

Fig. 7 Scatter diagrams for a magnetite mineral fraction and b thermal conductivity for artificial specimen $\lambda_{\text {Art }}$ normalized by the thermal conductivity of intact Toyoura sand $\lambda_{\text {Int }}$ as a function of

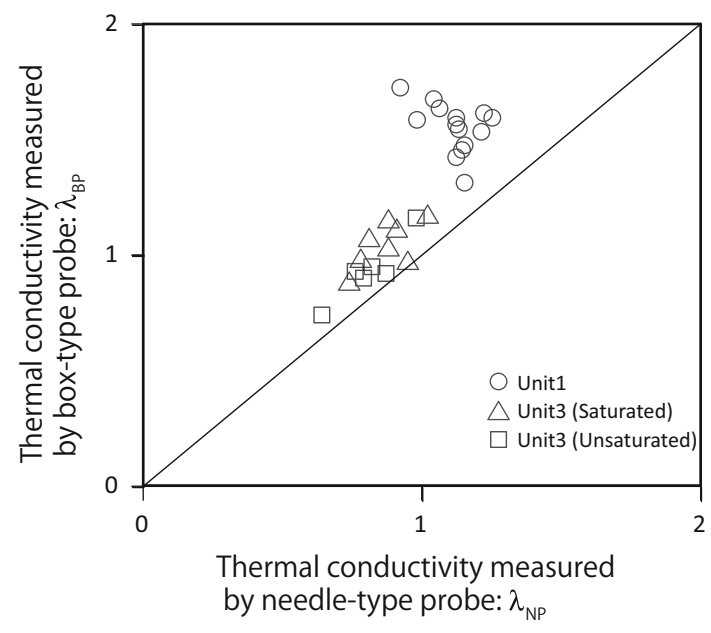

Fig. 8 Relationship between thermal conductivity measured using the box-type probe $\lambda_{\mathrm{BP}}$ and that measured using the needle-type probe $\lambda_{\mathrm{NP}}$

water-saturated soil, Ratcliffe (1960) reported that the thermal conductivity of marine sediment is a unique function of water content. Several models for estimating thermal conductivity have been proposed (Bullard and Day 1961; Lachenbruch and Marshall 1966; Saito et al. 2014). Woodside and Messmer (1961) developed a predictive model for thermal conductivity using the thermal conductivity values of water (seawater) and solid particles. In this model, the quartz content is an influential factor determining the thermal conductivity of solid particles (Johansen 1975; Tarnawski et al. 2009). The thermal conductivity of solid particles in the model was generalized for the thermal conductivity of each mineral component (Horai 1981; Drury and Jessop 1983; Vasseur et al. 1995).

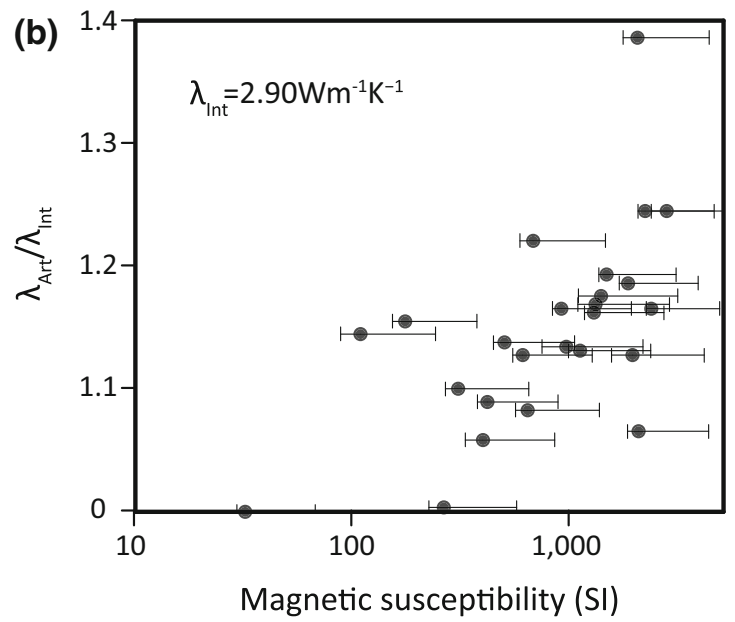

magnetic susceptibility. Plotted magnetic susceptibility is the mean value, and the error bar represents maximum and minimum values 


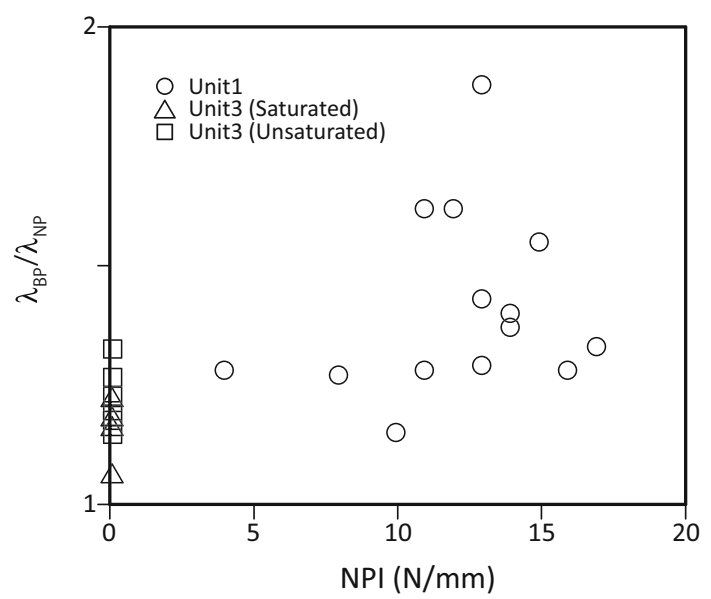

Fig. 9 Relationship between $\lambda_{\mathrm{BP}} / \lambda_{\mathrm{NP}}$ and the needle penetration index (NPI)

For example, Davis and Villinger (1992) estimated the depth profile of the thermal conductivity of Middle Valley sediments down to $2000 \mathrm{~m}$ using thermal conductivity of seawater and minerals (mica and clay minerals, quartz, feldspar, calcite, dolomite and chlorite). Midttømme et al. (1998) discussed the effect of mineralogy on thermal conductivity of claystones and mudstones of London Clay. The content of quartz and pyrite had a large effect on the thermal conductivity because these minerals have high thermal conductivity (Table 1).

In the proposed estimation model related to mineral composition, the important influencing factor was quartz or pyrite. It is true that the thermal conductivities of quartz and pyrite are more than twice those of other minerals except magnetic minerals. However, the sediments of this study contained small amounts of quartz and pyrite (Fig. 3). This feature of mineral content is widely observed in Pleistocene volcanic sediments in Japan. For Pleistocene volcanic sediments, magnetic minerals are present instead of quartz and pyrite and can be measured quantitatively.
The thermal conductivity values of magnetic minerals as functions of water content, porosity, sand content and magnetic susceptibility are illustrated in Fig. 11. The $R^{2}$ value (the coefficient of determination) for the relationship between thermal conductivity and magnetic susceptibility is the highest, indicating that the magnetic susceptibility has a large effect on the thermal conductivity (Fig. 11a). Figure 11b-d shows a bubble chart, with the colour scale indicating the magnitude of magnetic susceptibility. The thermal conductivity clearly depends on the magnetic susceptibility, and variable data, i.e., those distant from the regression line, are present in relatively large numbers for high values of magnetic susceptibility. Thus, the thermal conductivity of sediments containing a large amount of magnetite is predisposed to be overestimated when the thermal conductivity is predicted using water content, porosity and sand content.

\section{Summary and conclusions}

Thermal conductivity is an important factor when GSHP systems are installed underground and must be estimated to determine the total length required for the heat exchanger (U-tube). To ensure appropriate measurement of thermal conductivity in Pleistocene volcanic sediments in Tokyo, Japan, we discussed the measurement method of thermal conductivity and the factors influencing the thermal conductivity of volcanic sediment, which has a low quartz content. The conclusions obtained from experiments using a drill core and boreholes are as follows:

1. The geological and thermal properties were measured using core samples from a borehole. We confirmed that the thermal conductivity is dependent on water content, porosity, sand content and magnetic susceptibility. In addition, the magnetic susceptibility has the highest correlation with thermal conductivity
Fig. 10 Microfocus X-ray computed tomography images of undisturbed core samples obtained from hole 1 . The white double circles in the images indicate the position of the needle-type probe, and the black portion is pore space filled with air. a Depth of $28.25 \mathrm{~m}$ below ground level in unit 1 . b Depth of $6.15 \mathrm{~m}$ below ground level in unit 3. All scale bars are $10 \mathrm{~mm}$

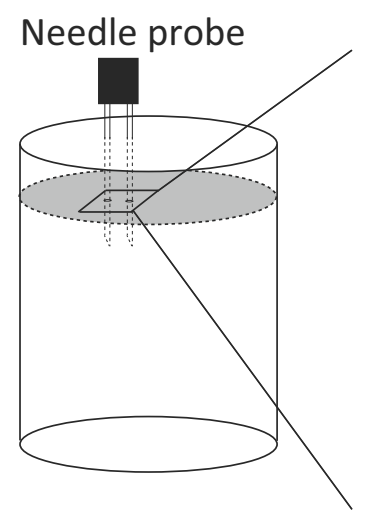

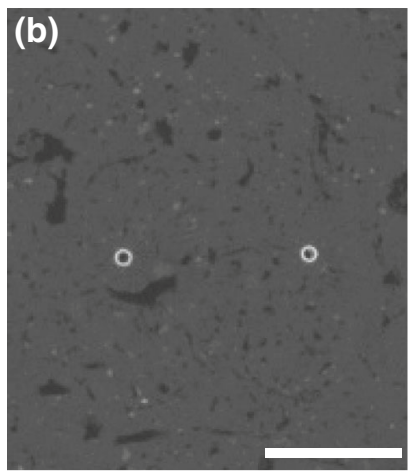



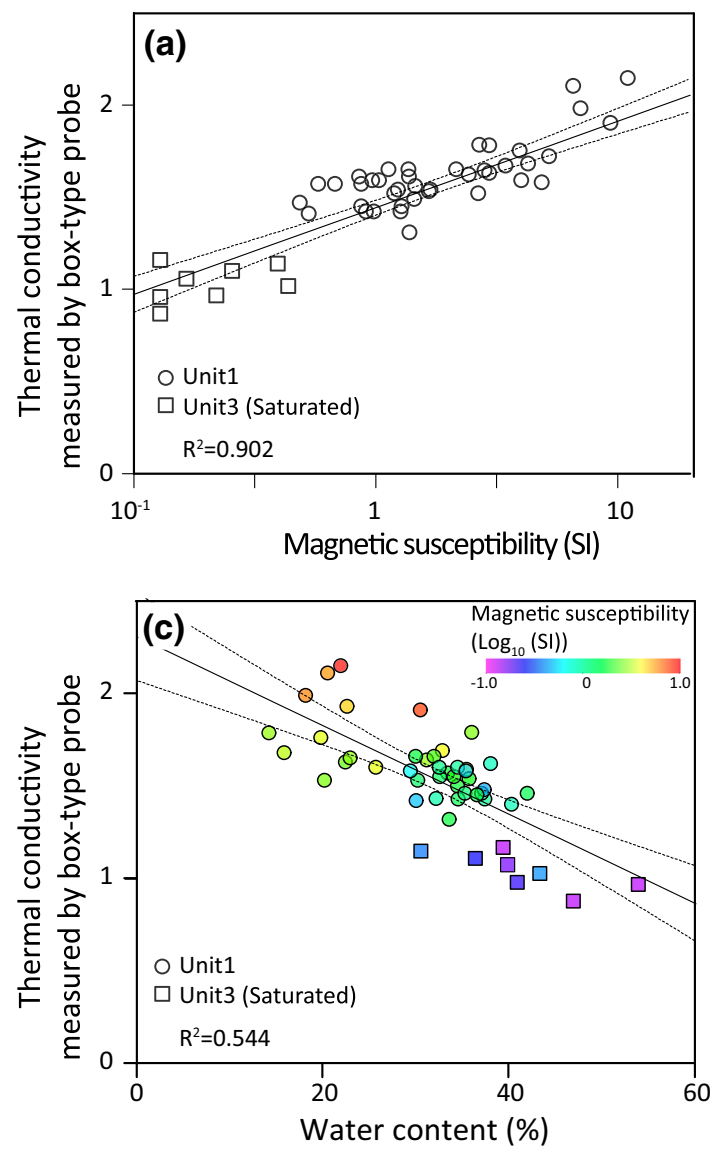

Fig. 11 Scatter diagrams of thermal conductivity as a function of a magnetic susceptibility, b porosity, $\mathbf{c}$ water content, and $\mathbf{d}$ sand content. The line and broken line in each graph denote the least-

compared with other geological properties, and the data variability became large with increasing magnetic susceptibility. Data variability should be given more attention because the thermal conductivity predicted using water content, porosity or sand content could be underestimated when measuring the thermal conductivity of volcanic sediment or sediments containing large amounts of magnetic minerals.

2. The relationship between magnetic susceptibility and thermal conductivity could be attributed to magnetic minerals, which have a higher thermal conductivity than quartz. This was confirmed by laboratory experiments that measured the effect of magnetite fraction on thermal conductivity using artificial sediment samples.

3. The thermal conductivities measured by two different methods, box- and needle-type probes, are not in good agreement. The values measured using a box-type probe are higher than those obtained using a needletype probe for consolidated/cemented sediments, possibly because an air-filled cracks are formed when the
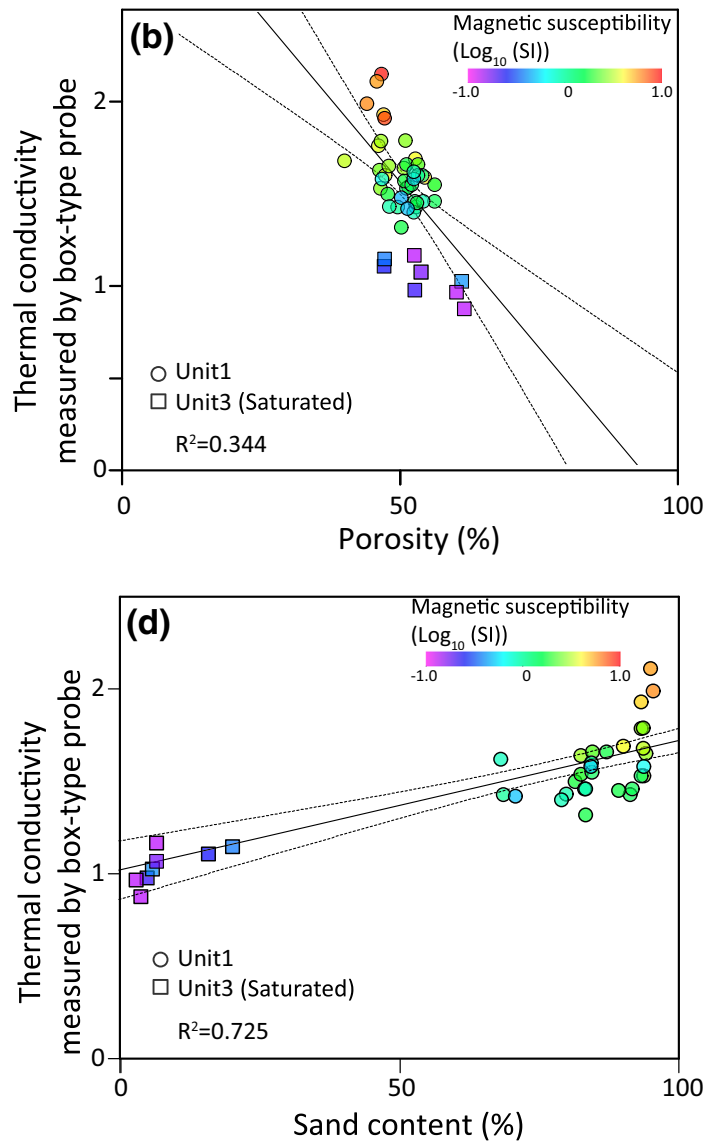

square line and the two-sided $95 \%$ confidence interval calculated using all data, respectively. The $\mathrm{R}^{2}$ value in the figures is the coefficient of determination

needle penetrates the sediment, as air has a lower thermal conductivity than sediment.

Acknowledgments This research was supported by the Core Research for Evolutionary Science and Technology (CREST) Program of the Japan Science and Technology Agency (JST), and partly supported by a Nihon University Chairman of the Board of Trustees grant. We thank Dr. Manabu Takahashi from the Geological Survey of Japan, AIST, and Dr. Weiren Lin from JAMSTEC for the useful discussions about thermal conductivity testing.

\section{References}

Akiyama T, Ogura G, Ohota H, Takahashi R, Waseda Y, Yagi J (1991) Thermal conductivities of dense iron oxides. J Iron Steel Inst Jpn 77:231-235 (in Japanese)

Arthur S, Streetly HR, Valley S, Streetly MJ, Herbert AW (2010) Modelling large ground source cooling systems in the Chalk aquifer of central London. Q J Eng Geol Hydrogeol 43:289-306

Banks D (2012) An introduction to thermogeology: ground source heating and cooling, 2nd edn. Wiley-Blackwell, Oxford. doi:10. 1002/9781118447512.ch1

Bullard EC, Day A (1961) The flow of heat through the floor of the Atlantic Ocean. Geophys J 4:282-292 
Busby J, Lewis M, Reeves H, Lawley R (2009) Initial geological considerations before installing ground source heat pump systems. Q J Eng Geol Hydrogeol 42:295-306

Davis EE, Villinger H (1992) Tectonic and thermal structure of the Middle Valley sedimented rift, northern Juan de Fuca Ridge. DSDP Init Repts 139:9-41

de Vries DA (1963) Thermal properties of soils. In: Van Wijk WR (ed) Physics of plant environment. North-Holland, Amsterdam, p 382

Drury MJ, Jessop AM (1983) The estimation of rock thermal conductivity from mineral content; assessment of techniques. Zentralbl Geol Palaeontol 1:35-48

Ellis DV, Singer JM (2007) Well logging for earth scientists, 2nd edn. Springer, The Netherlands, p 708

Galson DA, Wilson NP, Schärli U, Rybach L (1987) A comparison of the divided-bar and QTM methods of measuring thermal conductivity. Geothermics 16:215-226

Goto S, Matsubayashi O (2009) Relations between the thermal properties and porosity of sediments in the eastern flank of the Juan de Fuca Ridge. Earth Planets Sp 61:863-870

Horai K (1971) Thermal conductivity of rock forming minerals. J Geophys Res 76:1278-1308

Horai K (1981) Thermal conductivity of sediments and igneous rocks recovered during DSDP Leg 60. DSDP Init Repts 60:807-834

Ingersoll LR, Zobel OJ, Ingersoll AC (1948) Heat conduction with engineering and geological application. McGraw-Hill, New York, p 278

Ito M (1998) Submarine fan sequences of the lower Kazusa Group, a Plio-Pleistocene forearc basin fill in the Boso Peninsula, Japan. Sedimentary Geol 122:69-93

JGS (2009) Japanese standards for geotechnical and geoenvironmental investigation methods: standards and explanations. Standards of the Japanese Geotechnical Society, Tokyo, p 1190 (in Japanese)

Johansen O (1975) Thermal conductivity of soils. Ph.D. Thesis, University of Trondheim, Norway, p 321

Kasubuchi T (1984) Heat conduction model of saturated soil and estimation of thermal conductivity of soil solid phase. Soil Sci 138:240-247

Lachenbruch AH, Marshall BV (1966) Heat flow through the Arctic Ocean floor: the Canada Basin-Alpha Rise boundary. J Geophys Res 71:1223-1248

Lee C, Park M, Nguyen TB, Sohn B, Choi JM, Choi H (2012) Performance evaluation of closed-loop vertical ground heat exchangers by conducting in situ thermal response tests. Renew Energy 42:77-83

Liebel HT, Stølen MS, Frengstad BS, Ramstad RK, Brattli B (2012) Insights into the reliability of different thermal conductivity measurement techniques: a thermo-geological study in Mære (Norway). Bull Eng Geol Environ 71:235-243

Lin W, Tadai O, Hirose T, Tanikawa W, Takahashi M, Mukoyoshi H, Kinoshita M (2011) Thermal conductivities under high pressure in core samples from IODP NanTroSEIZE drilling site C0001. Geochem Geophys Geosyst. doi:10.1029/2010GC003449

Lin W, Fulton PM, Harris RN, Tadai O, Matsubayashi O, Tanikawa W, Kinoshita M (2014) Thermal conductivities, thermal diffusivities, and volumetric heat capacities of core samples obtained from the Japan Trench Fast Drilling Project (JFAST). Earth Planets Sp 66:48. doi:10.1186/1880-5981-66-48

Lund JW, Freeston DH, Boyd TL (2011) Direct utilization of geothermal energy: 2010 Worldwide review. Geothermics 40:159-180
Menberg K, Bayer P, Zosseder K, Rumohr S, Blum P (2013) Subsurface urban heat islands in German cities. Sci Total Environ 442:123-133

Midttømme K, Roaldset E, Aagaard P (1998) Thermal conductivity of selected claystones and mudstones from England. Clay Miner 33:131-145

Mielke P, Bauer D, Homuth S, Götz AE, Sass I (2014) Thermal effect of a borehole thermal energy store on the subsurface. Geotherm Energy 2:5. doi:10.1186/s40517-014-0005-1

Mølgaard J, Smeltzer WW (1971) Thermal conductivity of magnetite and hematite. J Appl Phys 42:3644-3647

Ochsner K (2007) Geothermal heat pumps: a guide for planning and installing. Earthscan, New York, p 146

Oka S, Kikuchi T, Katsurajima S (1984) Geology of the Tokyo Seinanbu district, quadrangle series, 1:50,000. Geological Survey of Japan, Tsukuba, p 148 (in Japanese)

Pribnow DFC, Sass JH (1995) Determination of thermal conductivity for deep boreholes. J Geophys Res 100:9981-9994

Ratcliffe EH (1960) Thermal conductivities of ocean sediments. J Geophys Res 65:1535-1541

Saito T, Hamamoto S, Mon EE, Takemura T, Saito H, Komatsu T, Moldrup P (2014) Thermal properties of boring core samples from the Kanto area, Japan: development of predictive models for thermal conductivity and diffusivity. Soils Found 54:116-125

Sass JH, Lachenbruch AH, Munroe R (1971) Thermal conductivity of rocks from measurements on fragments and its application to heat flow determinations. J Geophys Res 76:3391-3401

Schön JH (1996) Physical properties of rocks: fundamentals and principles of petrophysics, 1st edn. Pergamon Press, Oxford, p 583

Suzuki T, Obara M, Aoki T, Murata M, Kawashima S, Kawai M, Nakayama T, Tokizane K (2011) Identification of lower Pleistocene tephras under Tokyo and reconstruction of Quaternary crustal movements, Kanto tectonic basin, central Japan. Quat Int 246:247-259

Tadai O, Lin W, Tanikawa W, Hirose T, Sakaguchi M (2009) Technical note on thermal conductivity measurement for drilled core samples. JAMSTEC Rep Res Dev 9:1-14

Taniguchi M, Uemura T (2005) Effects of urbanization and groundwater flow on the subsurface temperature in Osaka, Japan. Phys Earth Planet Inter 152:305-313

Tarnawski VR, Momose T, Leong WH (2009) Assessing the impact of quartz content on the prediction of soil thermal conductivity. Geotechnique 59:331-338

Ulusay R, Aydan Ö, Erguler ZA, Ngan-Tillard DJM, Seiki T, Verwaal W, Sasaki Y, Sato S (2014) ISRM suggested method for the needle penetration test. Rock Mech and Rock Eng 47:1073-1085

Usowicz B (1992) Statistical-physical model of thermal conductivity in soil. Polish J soil Sci XXV/1. PL ISSN 0079-2985

Vasseur G, Brigaud F, Demongodin L (1995) Thermal conductivity estimation in sedimentary basins. Tectonophysics 244:167-174

Vosteen HD, Schellschmidt R (2003) Influence of temperature on thermal conductivity, thermalcapacity and thermal diffusivity for different types of rock. Phys Chemist Earth 28:499-509

Wagner R, Clauser C (2005) Evaluating thermal response tests using parameter estimation for thermal conductivity and thermal capacity. J Geophys Eng 2:349-356

Woodside W, Messmer JH (1961) Thermal conductivity of porous media. I. Unconsolidated sands. J Appl Phys 32:1688-1699 